\title{
Social Bonds as an Instrument of Responsible Investment
}

http://doi.org/10.21272/fmir.4(4).119-128.2020

Yuliya Yelnikova, ORCID: https://orcid.org/0000-0002-8478-4716

$\mathrm{PhD}$, assistant professor, Department of Accounting and Tax, Sumy State University, Sumy, Ukraine

\section{Irina Golochalova}

Conference (Associate professor), Doctor of economics, State University of Moldova, Department of Accounting and Economic Informatics, Chișinău, Moldova

\begin{abstract}
Research dedicated to structuring the scientific sphere in social bonds as an instrument responsible investing. The purpose of the paper is to form an information and bibliographic field of research of social bonds as tools of VI and their statistical support in the context of a new type of SIP. It was found that social bonds as a publicprivate partnership aimed at achieving financial, social impact and influence on the development fully meets the criteria of the VI instrument, but is studied primarily in the context of the empirical. The reason for this is the fact that the keys were based on practical use, and there is a large number of publications on a wide range of topics in the Scopus database without specifying the sound supply of the arms of 11,207 documents. A donation for the analysis of the informational-biometric field of social oblasts as for the tool BI will be received from the number of publications indexed by Scopus (Elsevir). Hours of progress for analysis at the end of 15 years (2005-2020 years). As for the research methodology, it is quite broad and includes built-in tools for analyzing the publication of the Scopus database, which provide a general idea of the information and bibliometric field of social bonds, software bibliometric analysis based on VOSviewer 1.6.15 for clustering analyzed publications with subsequent visualization, Google tools Trends and Google Data to study Internet search activity information and statistics for this tool. The first two methods allowed to analyze the publishing activity on the studied tools in academic circles on the leading base of scientific publications. The third is to describe the current trends in the development of information and statistical support of social bonds. The application of these methods for structuring the scientific sphere of social bonds allowed to justify its status as one that is formed and requires additional information and statistical support.
\end{abstract}

Keywords:. social bonds, responsible investing, Scopus (Elsevir), VOSviewer.

JEL Classification: G12, G38.

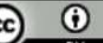

Cite as: Yelnikova, Y., Golochalova, I. (2020). Social Bonds as an Instrument of Responsible Investment. Financial Markets, Institutions and Risks, 4(4), 119-128. http://doi.org/10.21272/fmir.4(4).119-128.2020.

\section{Introduction}

Existing tools for responsible investment (VI) is quite diverse, since it takes into account numerous combinations of not only traditional investment parameters return, but also compliance with one (or the entire set) EESG / SDG criteria (ethical, environmental, social and governance / sustainable development goals).

Based on their unconditional advantage - uniqueness, individual tools can be considered the needs of individual investors, flexibly adapt to market needs. Such instruments include social bonds (Social Impact Bonds, Development Bonds or Results-Based Financing). In essence, they are not bonds but public-private partnerships, which allows private investors to invest capital in government projects that deliver social and environmental performance. If the project is successful, investors are paid interest with interest or the government (Social Impact Bonds) or an aid agency or other charitable foundation - Development Bonds Development impact bonds) If the project fails, capital and interest are lost. The yield on such bonds is usually around $7-8 \%$. This tool essentially replicates the payment-for-result scheme. This approach is also referred to as a fee for pay-for-success in the United States and as a social security bond in Australia . It should not be compared to commercial bonds, "green" bonds or other impact investments. Social bonds are usually linked to national social performance (UNCTAD (2020 a).

Comparison of potential advantages, disadvantages, risks in the use of these financial solutions in the context of application as a tool of new type of DIP lies not only in practice-oriented study (as it happened until 
recently), but also the formation of scientific arguments for their implementation. According to the preliminary analysis, these tools are mostly used by investors and portfolio managers, their essence and features of circulation are in the plane of empirical experience, analysis of industry and information organizations, financial regulators, rather than the subject of careful academic review. The purpose of the paper is to form an information and bibliographic field of research of social bonds as tools of VI and their statistical support in the context of a new type of SIP.

\section{Literature Review}

In order to form approaches to understanding the essence of ARVI instruments, including social bonds and their impact on financing sustainable development, investment decision-making processes, taking into account financial efficiency and socio-environmental impact by a number of international organizations (UN Development Program, the Sustainability Accounting Standards Board, the Global Reporting Initiative, OECD, the International Finance Corporation, the Global Impact Investing Network) in 2020 created by the Impact Management Project (IMP) Structured Network (OECD 2020).

The network's website provides information on the latest VI instruments, their areas of influence and the assets in which such investments are made. This network is a good example of coordination of efforts to develop and standardize approaches to streamlining new technologies and tools VI.

In this context, various organizations in the field of sustainable development publish their own lists of VI tools that can contribute to progress in achieving CSR.

According to the experts of the Business and Sustainable Development Commission, such instruments include development impact bonds (DIBs), green bonds, crowdfunding platforms, new types insurance products and technology Blockchain (Business and Sustainable Development Commission (2017)) Social bonds in this list are considered as development bonds.

Experts from the European Political Strategy Center also include "green" bonds in Poland ("green" sovereign bonds in Poland, "green" mortgage bonds for energy-efficient homes in Denmark) as key instruments for financing sustainable development. In addition to bonds, such instruments include sustainably labeled index funds and securities of environmentally friendly companies, green loans (energy efficient mortgages), and green securitization (EPSC) (2017). on the environmental aspects of VI instruments, however, development bonds can be used to address environmental issues.

Considering the abovementioned top priority for a new type of investment and investment program, the most suitable is the base of financial decisions (instruments) aimed at financing sustainable development (UNCTAD (2020 b). In it, social bonds are considered as instruments for generating income, in the form of debt securities with Therefore, these tools fully comply with the criteria of the VI tool and require systematization of the scientific landscape in its research. The reason for this is the facts, the key sources are worked out practiceoriented, and the total number of publications on this topic in the database Scopus reaches 11,207 documents without refining search queries.

\section{Data and Methodology}

Data selection for the analysis of the information and bibliometric field of social bonds as a tool of VI is carried out from the number of publications indexed by Scopus (Elsevir). The time intervals for the analysis cover the last 15 years (2005-2020). Although the first publications appeared in 1969, 21 articles were published in 2001-2005, the main array of publications was concentrated in 2005-2020.

As for the research methodology, it is quite broad and includes built-in tools for analyzing the publication of the Scopus database, which provide a general idea of the information and bibliometric field of social bonds, software bibliometric analysis based on VOSviewer 1.6.15 for clustering analyzed publications with subsequent visualization, Google tools Trends and Google Data to study Internet search activity information and statistics for this VI tool. 


\section{Results}

Filtering 11,207 documents in view of clarifying requests context of investment policy (social bonds AND (investment AND policy) received 530 publications. Using the built-in analysis tools scientific publications Scopus was built dynamic range of publications in years 2005-2020. (Figure 1 )

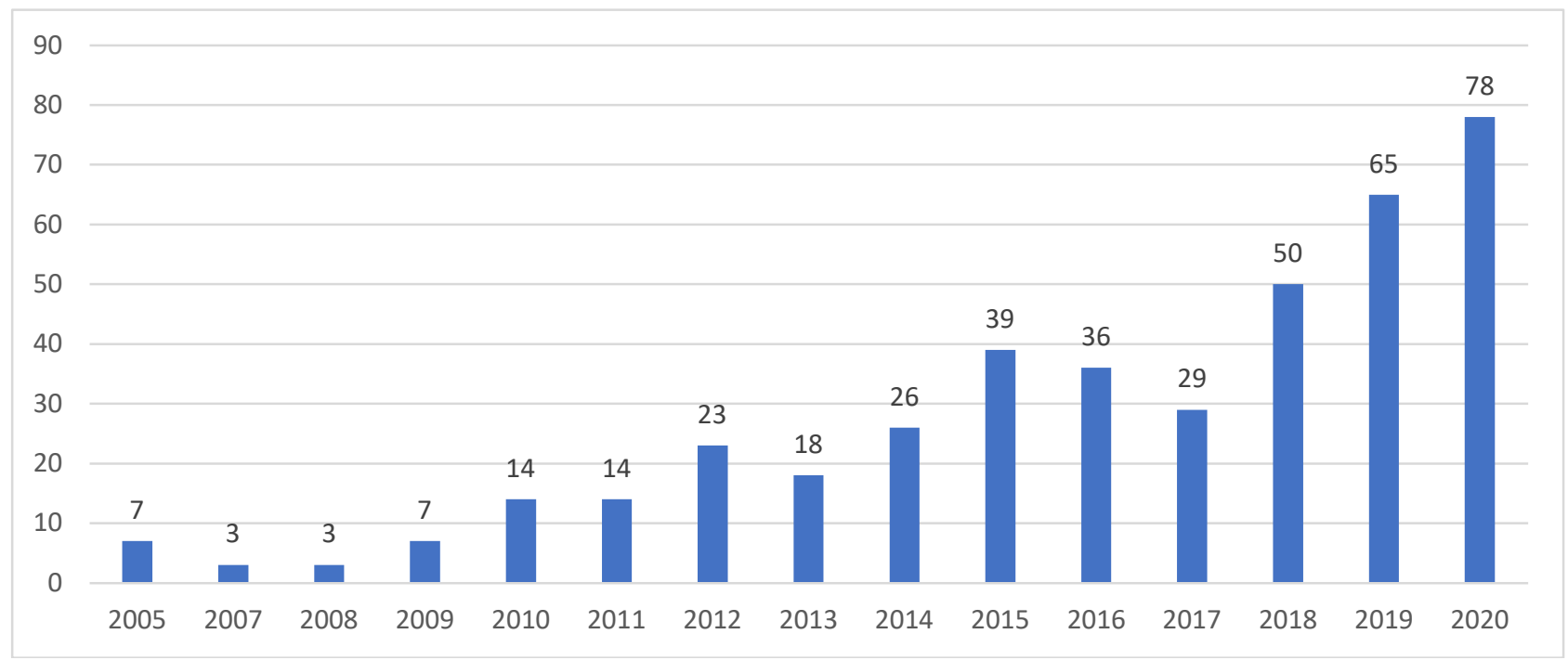

Figure 1. Publications by search terms "social bonds" in the context of investment policy in 2005-2020.

Source: author's development according to Scopus database.

As you can see, a significant increase in the number of publications on the analyzed topic occurs in 2018 2020, as well as in the period 2015-2016, which may be associated with the deployment of tools for socially oriented policies in the context of sustainable development in recent years and with the intensification of efforts of supranational organizations in the adoption of the global system of CSW in 2015

The structural analysis of the subject area of social bonds in the light of the new type of DIP (Figure 2) shows the prevalence of the economic context of their study.

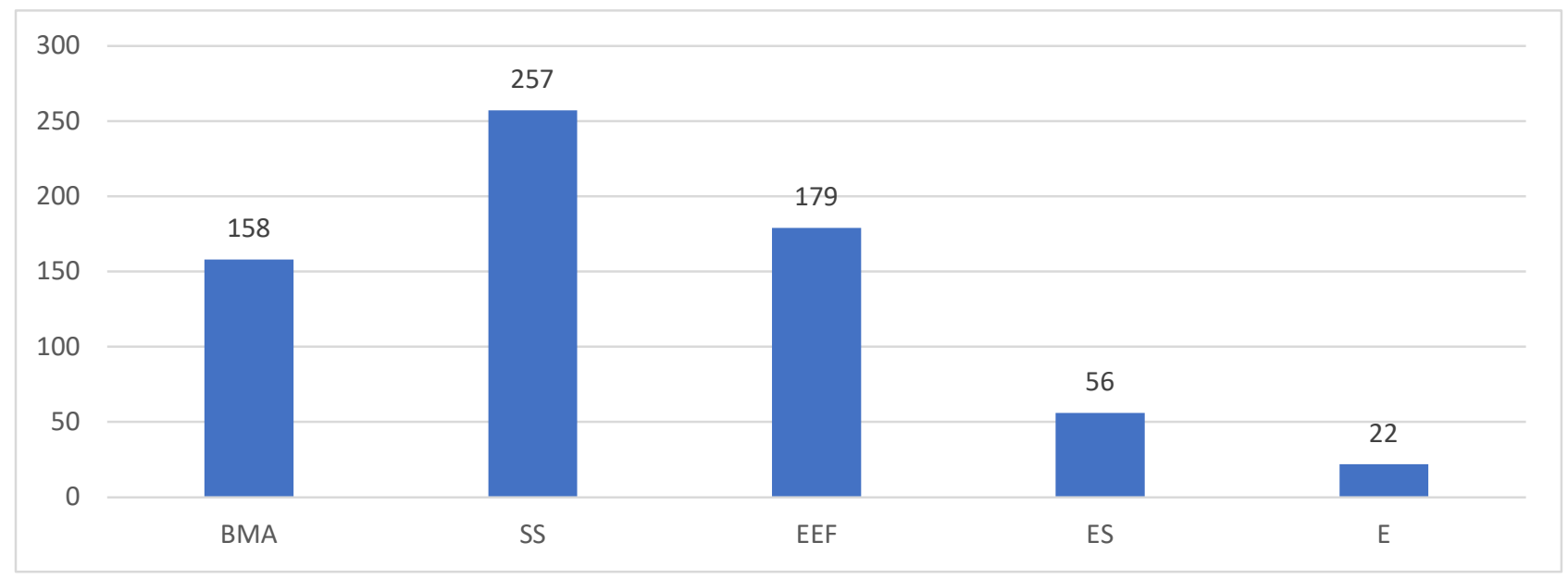

Figure 2 Subject area of study of social bonds in 2005-2020.

BMA (Business, Management and Accounting); SS (Social Sciences); EEF (Economy, Econometric and Finance); ES (Environmetal Scieinces); E (Energy.

Source: author's development according to Scopus database.

Despite the interdisciplinary research of these tools for financing sustainable development, for social bonds the predominant subject area is social sciences (257 publications from among the subjects), economics, econometrics and finance, as well as business, management and accounting.

Analyzing the most significant sources of publications (Table 1), it is worth emphasizing the rather frequent intersection of the most rated and well-known scientific journals for the publication of achievements on VI tools. 
Table 1 . Top of 10 journals by the number of publications about social bonds

\begin{tabular}{|l|l|}
\hline \multicolumn{1}{|c|}{ Journal } & \\
\hline Sustainability Switzerland & 14 \\
\hline Ahuri Final Report & 11 \\
\hline Public Money and Management & 11 \\
\hline Journal of Urban Affairs & 7 \\
\hline China and World Economy & 6 \\
\hline Journal of Economic Policy Reform & 6 \\
\hline Journal of Comparative Policy Analysis Research And Practice & 5 \\
\hline Research in International Business and Finance & 5 \\
\hline Environment and Planning A & 4 \\
\hline Journal of Sustainable Finance and Investment & 4 \\
\hline
\end{tabular}

Source: author's development according to Scopus

In the case of social bonds, the 3 most popular scientific journals include Sustainability Switzerland, Ahuri Final Report and Public Money And Management. The distribution of scientific publications by country of publication (Fig. 3) shows that the United States and the United Kingdom are the undisputed leaders in the world in the number of publications on social bonds (1st and 2 nd place).

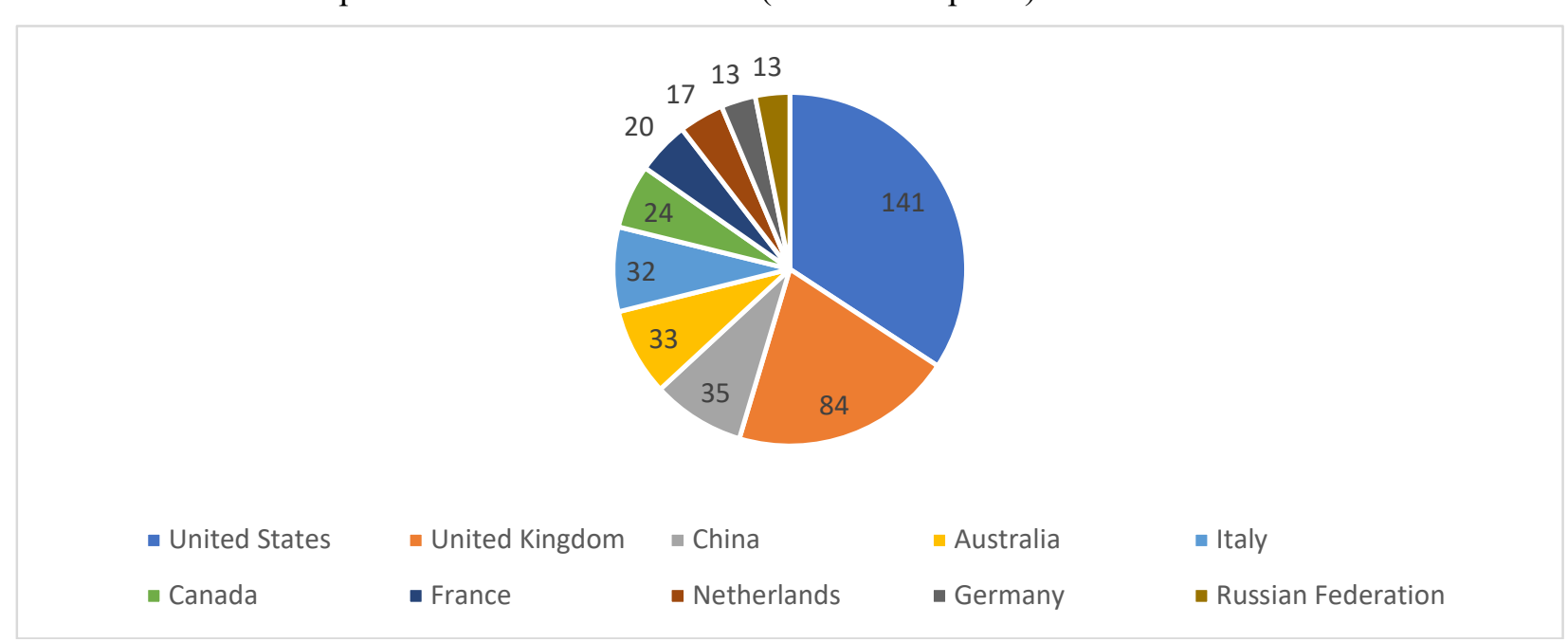

Figure 3. Top 10 countries in the world by the number of publications about social bonds for 2015-2020.

Source: author's development according to Scopus database.

At the same time, the topic of social bonds is predominant. The following division covers the EU, Australia, South Africa, Canada and Japan among the developed world, as well as Russia and China among developing countries. It should be noted that China ranks 3rd after the United States and the United Kingdom among all countries in the field of social bonds, given the large-scale steps to restructure the "green" financial system. The last direction of the analysis is the analysis of the authors of the studied arrays of articles in terms of financial instruments (Table 2). 5-6 articles have been published by the most productive scientists in the field of social bonds. Moreover, the closeness of the subject of impact investment and social bonds is confirmed at this level: Flatau, P. in both areas were published 5 articles, which consider social impact investment.

Table 2. Top 10 authors of scientific papers in terms of social bonds for 2005-2020.

\begin{tabular}{|l|c|}
\hline \multicolumn{1}{|c|}{ Scientist } & \multicolumn{1}{|c|}{ Article } \\
\hline Fraser, A. & 6 \\
\hline Flatau, P. & 5 \\
\hline Fox, C. & 5 \\
\hline Harvie, D. & 5 \\
\hline McHugh, N. & 5 \\
\hline Albertson, K. & 4 \\
\hline Carter, E. & 4 \\
\hline Kimmitt, J. & 4 \\
\hline Lawson, J. & 4 \\
\hline Sinclair, S. & 4 \\
\hline
\end{tabular}

Source: author's development according to Scopus database. 
The results obtained for the most well-known scientists researching a particular tool are in-depth using the VOS Viewer toolkit. It was used to select the following clusters of researchers from the list in Table 2 and visualize the network connections between them based on the co-authorship of the papers (Figure 4, See in Appendix).

As we can see, among the most well-known scientists in the field of social bonds, only two scientific schools can be distinguished - the more productive - with the participation of McHugh, N., Sinclair, S., Roy, M. (McHugh, N. et al. 2013, Roy, MJ et al (2017), Sinclair, S. et al. (2019) and less productive - with the participation of Fraser, A. Carter, E. (Fraser, A., Carter, E. (2020). Fraser, A. and Carter, E. have significant achievements in the field of social bonds, prepared without joint authorship. (Carter, E. (2020), Carter, E. (2019), Fraser, A., \& Lowe, T. 2020), FitzGerald, Fraser, A., \& Kimmitt, J. (2020) The rest of the scientists are represented outside the scientific schools.

The application of VOS Viewer tools to the researched array of articles on social bonds by keywords allowed to systematize and visualize the scientific landscape by areas and related areas of research and illustrate their academic importance, taking into account the chronological aspect.

A study of social bonds based on 5 shingle keyword patterns revealed 58 such patterns, which were grouped into 4 clusters. (Figure 5, See in Appendix). As can be seen from the figure, the largest cluster is "red", which combines the study of social bonds in various terminological areas in combination with impact investment and social policy. Its additional description is given in table. 3. The smallest is the "yellow" cluster, which considers social bonds along with the concepts of sustainable development, "green" bonds, corporate social bonds.

Table 3. Clustering of scientists' achievements about social bonds based on keywords

\begin{tabular}{|l|c|c|c|}
\hline Clasters & Title & Colour & Keywords \\
\hline 1 & $\begin{array}{c}\text { Social bonds in the context of social } \\
\text { impact }\end{array}$ & Red & $\begin{array}{c}\text { Finance, financialization, impact investment, social impact bonds, social } \\
\text { impact investments, payment for the result, social policy, social investments. }\end{array}$ \\
\hline 2 & $\begin{array}{c}\text { Social bonds in the context of } \\
\text { financial and economic variables }\end{array}$ & Green & $\begin{array}{c}\text { Economic development, social security, banks, economy, capital market, } \\
\text { financial market, financial crisis, investment decisions }\end{array}$ \\
\hline 3 & Social bonds in context & Blue & State, public policy, public-private partnership, cost-benefit analysis \\
\hline 4 & $\begin{array}{c}\text { Social bonds in the context of } \\
\text { sustainable development }\end{array}$ & Yellow & $\begin{array}{c}\text { "Green" bonds, corporate social responsibility, sustainable development, social } \\
\text { networial capital }\end{array}$ \\
\hline
\end{tabular}

Source: author's development using VOS Viewer.

Both of these clusters are later in chronology, in 2017-2020 (Figure 6, see in Appendix).

The oldest (2012-2014) are publications that consider social bonds in the context of the general economic system. An important cluster in the context of the SIP is the "blue", which covers the publications of 20142016 on social bonds as an instrument of public policy and public-private partnership. However, investment policy is not among the keywords of this cluster. Terminological analysis of keywords for all VI tools allows us to draw an important conclusion - the identified clusters do not contain concepts that would relate to DIP, the role of VI in the formation of public strategy for sustainable development, financial support of CSW. There are only connections with the relevant family policies - social security. At the same time, there is a clear contextual link between social bonds and social finances. After using the built-in Scopus tools for analyzing social bond publications as VI tools and their bibliometric analysis using VOS Viewer, the final stage in shaping the scientific landscape of these tools is the use of Google Trends and Google Data tools. Their use is aimed at studying the activity of searching the Internet for information and statistics on social bonds in the applied aspect. The general dynamics of search queries on the studied tools (Figure 7) indicates the prevalence of search activity of users for social bonds in 2005-2007 (single queries) and in 2011-2016 (more systematic). The dynamics of scientific publications only partially correlates with the empirical interest in social bonds (2015-2016 study). 


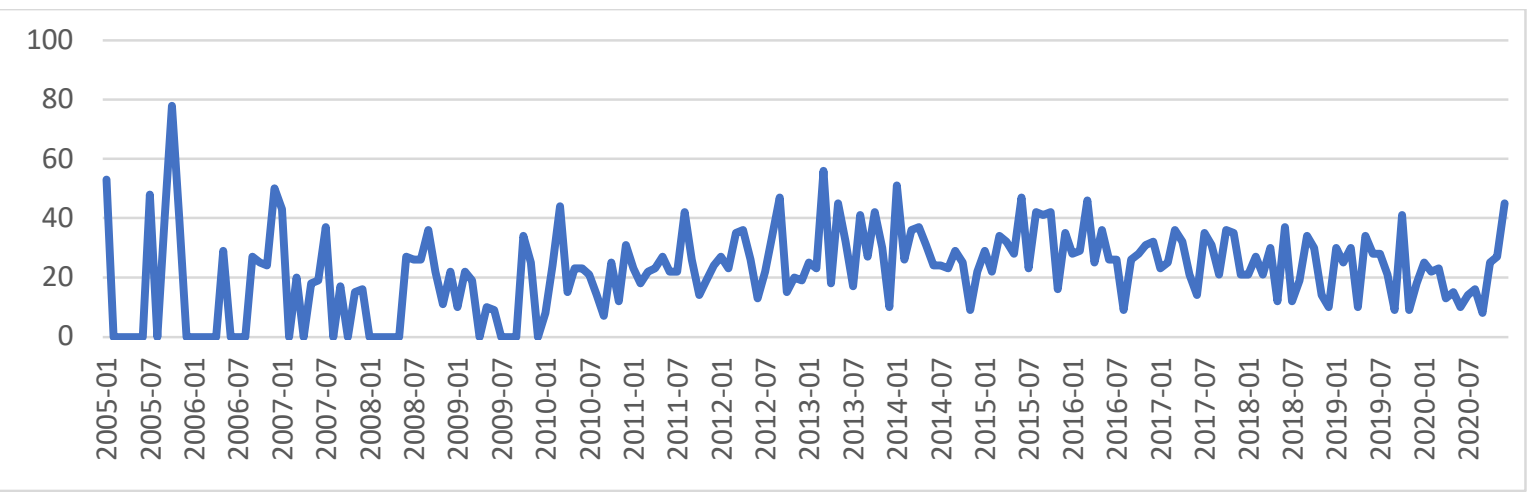

Figure 7. User requests from the Internet for social bonds 2004-2020, Requests per month

Source: compiled by the authors using Google trends.

The regional profile of the queries under consideration, formed by means of Google trends, indicates that social bonds are the subject of interest of users from Anglo-American countries, which is confirmed taking into account the prevalence of the social trend in the Anglo-American pattern of ARVI. The analysis of data sets on social bonds as a VI toolkit by means of Google dataset search for the last 3 years (by update criterion) was carried out with the exception of the sites www.statista.com, data.mendeley.com, search.datacite.org. Table 4 shows the most popular data on ARVI instrumentation.

Table 4. Top 5 most popular data sets about VI tools

\begin{tabular}{|l|l|}
\hline Place & \multicolumn{1}{|c|}{ Data set } \\
\hline 1 & $\begin{array}{l}\text { Data from: Social Bonds Across Immigration Generations and the Immigrant School Enclave: A Multilevel Longitudinal Study of Student } \\
\text { Violence, School Disorder, and Dropping Out, United States } \\
\text { https://www.icpsr.umich.edu/web/NACJD/studies/35647 }\end{array}$ \\
\hline 2 & $\begin{array}{l}\text { Data from: Social Ties and the Selection of China's Political Elite } \\
\text { datadryad.org } \\
\text { search.datacite.org }\end{array}$ \\
\hline 3 & $\begin{array}{l}\text { Mergent Municipal Bond Data } \\
\text { dataverse.harvard.edu }\end{array}$ \\
\hline 4 & $\begin{array}{l}\text { Social Impact Bonds Centre for SIBs mailing list } \\
\text { www.europeandataportal.eu } \\
\text { data.gov.uk }\end{array}$ \\
\hline 5 & $\begin{array}{l}\text { Emission UNEDIC - Social Bond - 202005 } \\
\text { data.rsedatanews.net }\end{array}$ \\
\hline
\end{tabular}

Source: compiled by the author using Google dataset search.

These data sets indicate insufficient information and statistical support of the studied tools VI. Data on social bonds are contained mainly in scientific sources and some European and British statistical services.

\section{Conclusions, discussion and recommendations}

Based on the empirical approach to understanding social bonds as tools of VI and public-private partnership, aimed at achieving social effect and impact on development, a comprehensive review of the modern information and bibliometric field, scientific trends and features of their study in the context of SIP. Data are selected for analysis from the number of publications indexed by Scopus (Elsevir). The time intervals for the analysis cover the last 15 years (2005-2020). The analysis was performed using Scopus, VOSviewer 1.6.15 Google Trends and Google Data

Thus, according to the chronology of scientific publications, social bonds are the most studied category from the second half of the 20th century, within such subject areas as social sciences, economics, econometrics and finance, business and accounting. The application of VOS Viewer tools to the studied array of articles in terms of VI tools by keywords allowed to systematize and visualize the scientific sphere of two scientific schools in the field of social bonds (with McHugh, N., Sinclair, S., Roy, M. (McHugh, N . et al. 2013, Roy, MJ et al (2017), Sinclair, S. et al. (2019) and featuring Fraser, A. Carter, E. (Fraser, A., Carter, E. (2020).

In terms of meaningful clustering of publications on social bonds by keywords, most research is concentrated in the cluster that associates these bonds with impact investment and social policy. This positioning of social bonds is the latest in scientific circles, as well as their consideration along with the concepts of sustainable 
development, "green" bonds, corporate social bonds. Analysis of Internet users' requests for social bonds, generated by Google trends, shows that they are of interest to most users from Anglo-American countries in 2011-2016, which is confirmed given the predominance of social orientation in the Anglo-American pattern VI. However, the information and statistical support for the study of these bonds does not contain regular sources. The results of the analysis of the array of scientific publications on social bonds as a tool of VI, conducted by Scopus, VOSviewer 1.6.15 Google Trends and Google Data show that the scientific sphere in this area is in its infancy, due to the predominant use of these bonds as an empirical tool. aimed at addressing social policy issues.

Author Contributions: conceptualization, Julia Yelnikova; data curation, Irina Golochalova; formal analysis, Irina Golochalova; funding acquisition, Julia Yelnikova; investigation, Julia Yelnikova; methodology, Julia Yelnikova; project administration, Irina Golochalova; resources, Julia Yelnikova; software, Julia Yelnikova; supervision, Julia Yelnikova; validation, Julia Yelnikova; visualization, Irina Golochalova; writing - original draft, Irina Golochalova; writing - review \& editing, Julia Yelnikova

\section{References}

1. Business and Sustainable Development Commission (2017) Better Business, Better World. https://susta inabledevelopment.un.org/index.php?page $=$ view \&type $=400 \& n r=2399 \& m e n u=1515$

2. Carter, E. (2019). More than marketised? exploring the governance and accountability mechanisms at play in social impact bonds. Journal of Economic Policy Reform, doi:10.1080/17487870.2019.1575736

3. Carter, E. (2020). Debate: Would a social impact bond by any other name smell as sweet? stretching the model and why it might matter. Public Money and Management, 40(3), 183-185. doi:10.1080/09540962.2020.1714288

4. Dayson, C., Fraser, A., \& Lowe, T. (2020). A comparative analysis of social impact bond and conventional financing approaches to health service commissioning in england: The case of social prescribing. Journal of Comparative Policy Analysis: Research and Practice, 22(2), 153-169. doi:10.1080/13876988.2019.1643614

5. EPSC (2017) Financing Sustainability Triggering Investments for the Clean Economy. European Political Strategy Centre notes 25. Retrieved from: https://gsgii.org/wp-content/uploads/2017/10/ strategic note issue 25.pdf

6. FitzGerald, C. L. A. R. E., Fraser, A., \& Kimmitt, J. (2020). Tackling the big questions in social impact bond research through comparative approaches. Journal of Comparative Policy Analysis: Research and Practice, 22(2), 85-99. doi:10.1080/13876988.2020.1726177

7. McHugh, N., Sinclair, S., Roy, M., Huckfield, L., \& Donaldson, C. (2013). Social impact bonds: A wolf in sheep's clothing? Journal of Poverty and Social Justice, 21(3), 247-257. doi:10.1332/204674313X13812372137921

8. OECD (2020) Shifting-public-and-private-finance-towards-the-sustainable-development-goal. Retrieved from: https://oecd-development-matters.org/2020/01/09/shifting-public-and-private-finance-towards-thesustainable-development-goals/

9. Roy, M. J., McHugh, N., \& Sinclair, S. (2017). Social impact bonds - evidence-based policy or ideology? Handbook of social policy evaluation, 263-275. doi:10.4337/9781785363245

10. Sinclair, S., McHugh, N., \& Roy, M. J. (2019). Social innovation, financialisation and commodification: A critique of social impact bonds. Journal of Economic Policy Reform, doi:10.1080/17487870.2019.1571415

11. UNCTAD (2020 a). Social-development-impact-bonds. Retrieved from: https://www.sdfinance.undp.org /content/sdfinance/en/home/solutions/social-development-impact-bonds.html

12. UNCTAD (2020 b). Financing Solutions for Sustainable Development. Retrieved from: https://www.sdfinance.undp.org/content/sdfinance/en/home/how-to-use-the-platform.html/

13. Wilson, R., Fraser, A., Kimmitt, J., Tan, S., McHugh, N., Lowe, T. Carter, E. (2020). Theme: Futures in social investment? learning from the emerging policy and practice of social impact bonds (SIBs): Editorial: Whither social impact bonds (SIBs): The future of social investment? Public Money and Management, 40(3), 179-182. doi:10.1080/09540962.2020.1714287 
harvie $\mathrm{d}$.

carèr.

schinckus c.

lawson j.

(1)

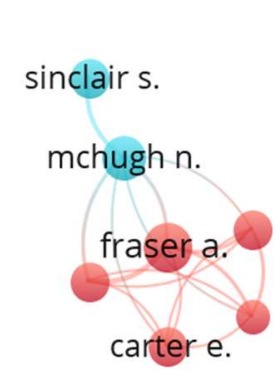

iovan s.

lantz p.m.

knoll I.

\section{象 VOSviewer}

Source: by the author using VOS Viewer.
Figure 4. Bibliometric map of publications on "social bonds" based on co-authorship 
child care

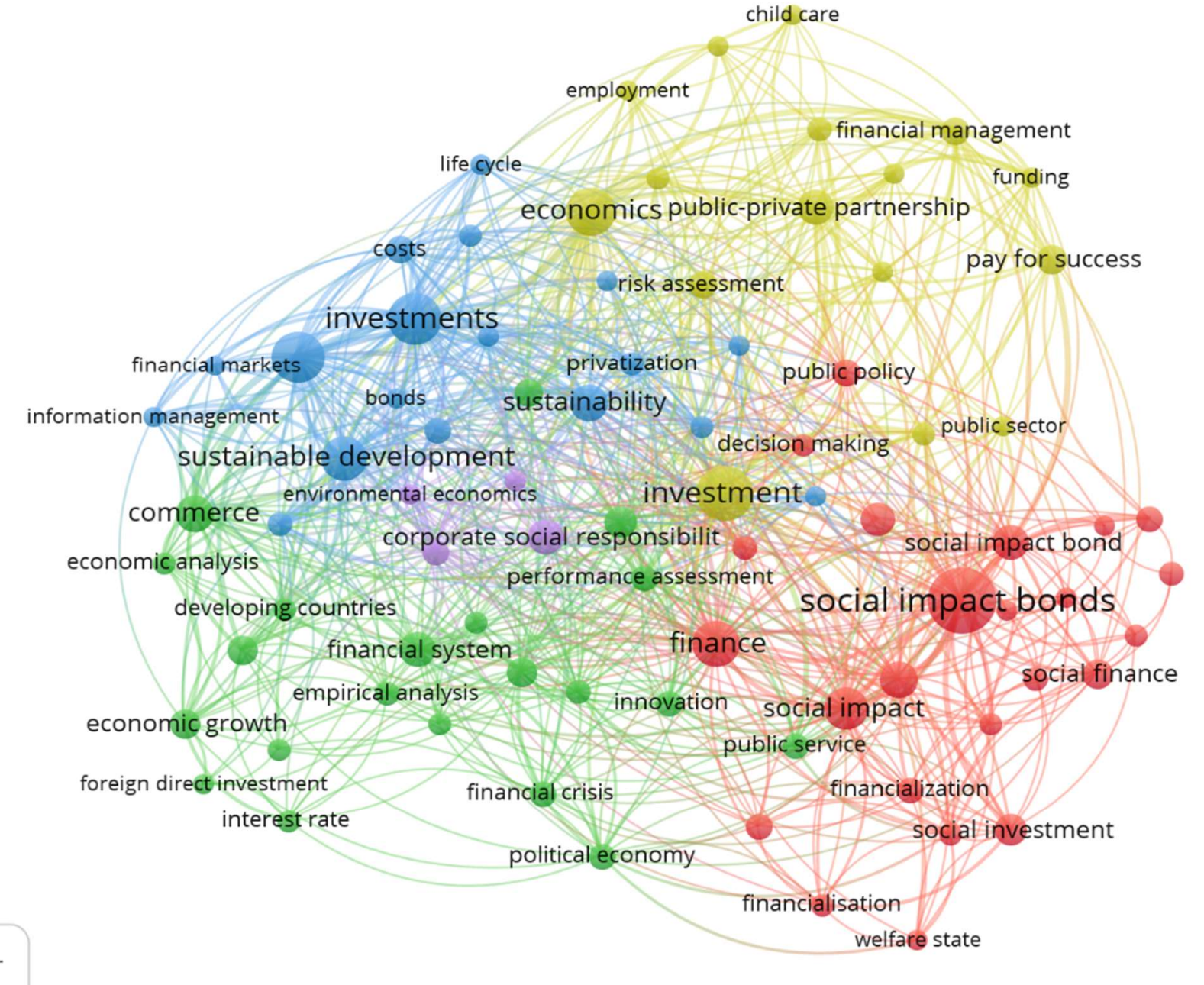

Figure 5. Bibliometric map of publications on "social bonds" based on keywords in 2005-2020. 


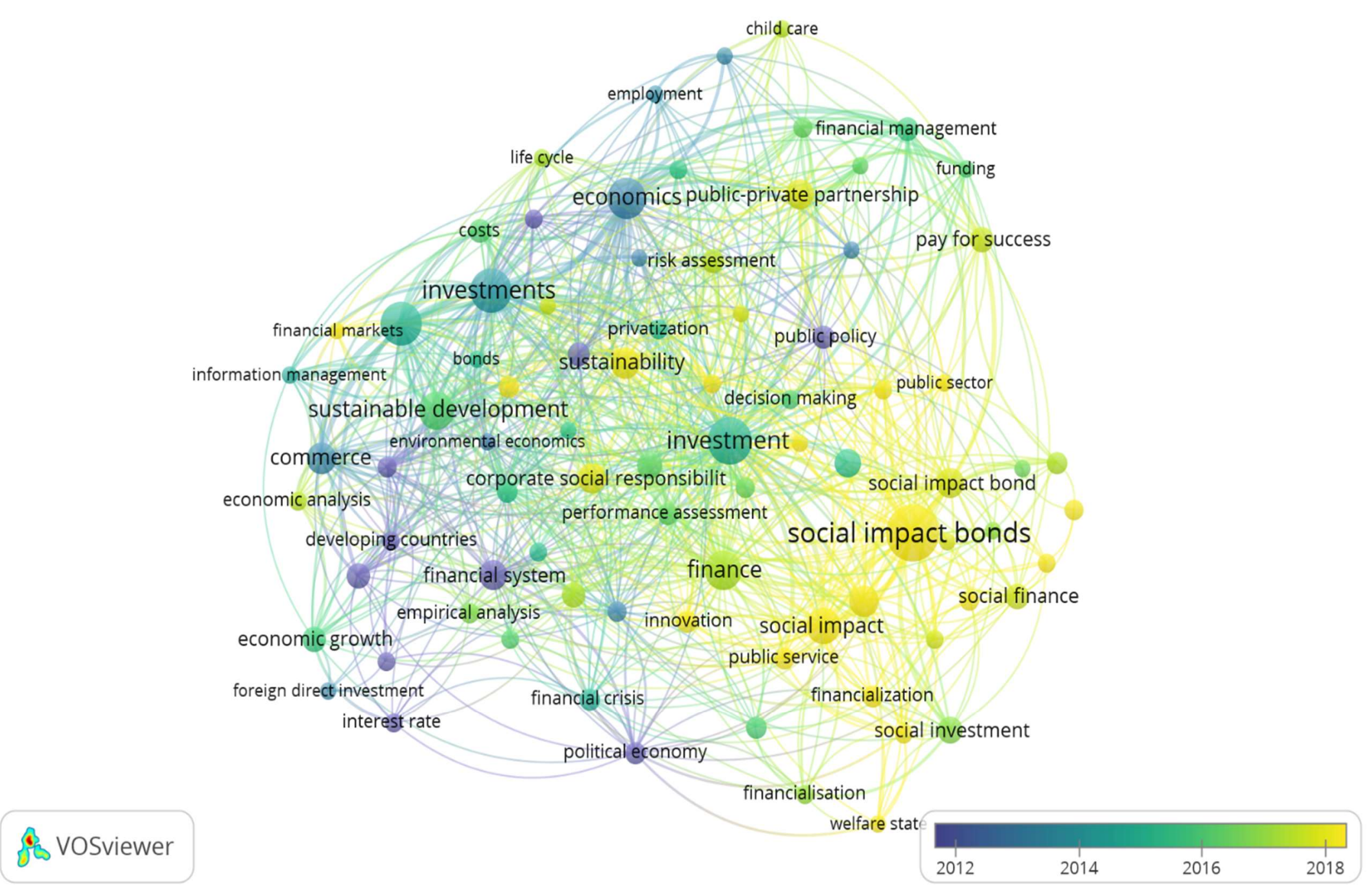

Figure 6. Bibliometric map of publications about "social bonds" based on keywords (chronological aspect)

Source: author's development using VOS Viewer. 